\title{
City transport as a factor of availability and distribution of activity centres
}

\author{
Alexander Gorovoy ${ }^{1}$, Igor Merzlikin ${ }^{2, *}$ and Tatyana Kondratyeva ${ }^{3}$ \\ ${ }^{1}$ Saint Petersburg National Research University of Information Technologies, Mechanics and Optics, \\ ITMO University, Kronverkskiy prospekt, 49, St. Petersburg, 197101, Russia \\ ${ }^{2}$ Moscow State Technical University of Civil Aviation, Kronshtadsky, 22, Moscow, 125009, Russia \\ ${ }^{3}$ Moscow State University of Civil Engineering, Yaroslavskoe shosse, 26, Moscow, 129337, Russia
}

\begin{abstract}
Labor connections determine territorial unity and spatiotemporal settlement patterns in the structure of city connections. Labor connections define the life of the city, the distribution of the centers of gravity, and the functioning of its main subsystems, the leading one being the transport subsystem. The study is constructed to reveal the trend of settlement (by labor gravitation) based on the effect of the desired choice of workplace location in relation to residence location. The results of the sociological survey allowed establishing the trend of settlement on the basis of the effect of the desired choice. The study discovered a correlation between the values characterizing the topological structure of the plan: a distinctive "scale of settlement" (average shortest distances between the settlement variant and workplace locations) and the internal heterogeneity of the plan (uneven concentration of facilities and their connections). This allows drafting settlement curves for cities without empirical data.
\end{abstract}

\section{Introduction}

The principal problem of laying out the most important connections and organizing the transportation in the city and the settlements that gravitate towards it is fulfilling the essential tasks of urban space planning. It is not our intention to consider it a problem of transportation facilities management or traffic organization, since these only arise as a result of ill planning. However, the highly topical issues of forming the systems of transport hubs within the structure of a modern megalopolis have been widely reflected in a number of studies by Russian researchers [1].

The reasons that have caused the need to predict the flow of people and transport within the existing planning structure and transport service systems fall within the domain of sociology. The formation of human and transport flows towards activity centers always follows four fundamental criteria: interest, salaries, career opportunities, and travel time to workplaces; and interest, comfort, cost, and travel time for all kinds of services. Surely, these criteria can also be applied when choosing places of residence.

\footnotetext{
*Corresponding author: tkondratieva@blackver.com
} 
In terms of day-to-day stability, the focus is on the most intensive labor connections, as their duration consistently defines the spatial boundaries of the city, regardless of the development of modes of transport. And it is labor connections that determine territorial unity and spatiotemporal settlement patterns. The formation, stabilization, and modification of these connections are most sensitive to changes of the planning structure in the process of urban expansion and renewal. The mechanism of labor connection formation and the identification of preferences in the selection process can thus be transferred to other similar phenomena, such as the nature of welfare and recreational connections. In general, they define the life of the city, the distribution of the centers of gravity, and the functioning of its main subsystems, the leading one being the transport subsystem.

The heterogeneity of urban space development, established by many researchers, draws attention to the nature and patterns of its usage. Evidently, they involve not only economic, but also social and psychological aspects $[2,3]$. These patterns are a prerequisite for the formation, development, and evolution of settlement systems; they are the product of the population's dynamic and purposeful activity. In this context, transport is a structure that implements the functioning of all the city's subsystems.

\section{Materials and Methods}

As a rule, the models of structural transformations are the subject of modeling the city's transport and pedestrian networks. The most notable among them are the methodological and practical developments by the school of V.M. Predtechensky - the movement of pedestrian flows towards centers of gravity - and the school of M.A. Yakshin - the study of transport subsystems. The main idea and its subsequent modifications are based on the key characteristics of the urban plan - the need for compactness - and on the "law" of uneven use of various city areas (for example, study [4] substantiates the impact of spatial parameters on the spatial structure of the city). Although the idea is not new, it provided the basis for developing constructive models and methods for operational design.

The theoretical basis for most of the models is the assumption of the existence of a state of the urban system that is capable of organizing the most convenient (optimal) form of its functioning based on the information on the choices and preferences of certain facilities within it. This information can be seen as a "field" for selecting between two or more values with known probabilities, which allows approaching all the processes with a single standard - the common language of research. In support of the above, let us consider some models and the methods of their potential solution.

Modeling assumes the existence of a complex of urban subsystems, a description of the processes of interaction between them, management at various levels (from pre-project studies to specific design stages), and a set of parameters with the property of controlling actions. At the same time, the models rely on actual information on the functioning of the city, entered in the form of indicators of socio-economic development for a set period [5].

Two alternative directions were developed within this approach: optimization models and "needs-satisfaction" models. The first direction is represented by normative models, the main advantage of which is obtaining possible targeted management strategies. These models have been well-tried and tested in transport issues, using mathematical programming methods. They include capacity restrictions on facility location, balance relationships between transport and pedestrian flows, budgetary constraints, and formalized management parameters, such as the cost of accommodation, the costs of arranging transportation, and traffic loads on arterial roads.

The identified incompleteness and orthodoxy of the conclusions provided by normative models stimulated the search for other approaches and led to the emergence of behavioral models (the second alternative). The principles upon which they are built are in complete 
contrast to the normative ones. They are entirely focused on simulating real urban development processes; they make it possible to obtain a wide range of assessments, but do not allow for a targeted search for the most suitable options.

Normative-behavioral models were developed in order to create a flexible tool. They are designed to combine the simulation models of functional processes with the possibilities of targeted formation of the optimal variant for urban system development. For instance, the activity of the transport subsystem is integrally linked with the location of workplaces, residential areas and the demographic and social structure of the population.

The most controversial issue, inherent in all the models simulating the functional process and the structure of relationships, is the value of interacting masses and connections between them. In models of the normative-behavioral type, it is the correspondence value between regions $j$ and $i$ with $\delta i j$ probability. In Wilson's models, it is function $f(C i, j)$, which, in essence, is a function of the social value of time and is usually established statistically.

The definition of the functional value of a city's territory-and within this framework, the intensity of its use - is the subject of both the models of spatial urban development and the models simulating the activity of functional subsystems. The best-known among them is the Lowry model. The model considers all the main activities of the population and the corresponding distribution of urban areas. Within the framework of the Regional Economic Study, it was applied in Pittsburgh, San Francisco, Boston, and Penn-Jersey.

The models of urban redevelopment and renewal constitute a special class of models [6, 7].

The new models forecast the spatial distribution of residences and the main forms of industry, the specificities of land use, employment, and the resources required for the implementation of urban redevelopment and renewal programs [8].

An important aspect of these models is achieving the interrelation of territorial development with economic opportunities, market analysis, the demographic structure of the population, and the resources and requirements of government authorities [9].

Their rational elements are: a) the interrelation of land development with the conditions of employment of the population; b) taking into account the effects of many random external factors on land development.

These models allow considering alternative forms of land use as well as the strategy of redeveloping and renovating old residential areas [10-12].

Forecasting models are based on the integration of the results of the statistical and urban analysis with the theoretical models of the development, growth, or decline of the city.

Thus, the purpose of the models analyzed is selecting the most rational solutions in urban redevelopment and renewal. When correctly used in the preparation of city master plans, the modeling concept can significantly contribute to eliminating potential errors in placing the key facilities and laying out the connections between them.

A methodology based on the analyzed models was developed to address the problems of forecasting and estimating the location of urban development areas. It is based on the study of human (city population) behavior patterns and the underlying nature of the choice of destinations. This allowed establishing the reason for the said choice and, consequently, the formation and direction of the movement of people and traffic.

The city dweller builds their own model and fills it with their own perception of the spacetime "scale." As a result of this activity, stable social ties between the person and the "place" as well as between people are forged; these ties essentially form the viability of urban processes. The activity of a person, a city dweller, also fills the functional structure of the city by linking the social, functional, and spatial aspects into a coherent whole. It thus sets the decision-making programs for the principal issues of the city master plan. Therefore, studying the behavior of city dwellers allows establishing their assessment of the "quality" of the urban environment (study [13] attempts to analyze the existing approaches to the 
definition of this concept). The focus is on the environment created on the basis of the patterns of the city dwellers' choice of various situations and workplace locations. Understanding them makes it possible to manage the urban system: to establish the centers of gravity and organize transportation.

Observation, scenario analysis, and questionnaires are deemed the only methods that represent a reliable approach to obtaining information on the patterns of the population's choice of different situations. We opted for the questionnaire method, with subsequent data processing using mathematical statistics.

The study is constructed to reveal the trend of settlement (by labor gravitation) based on the effect of the desired choice of workplace location in relation to residence location. The study considers areas with development potential, areas for renovation, and real transport links. The survey was conducted in three cities of similar population levels (population growth), size, production patterns, and climatic data.

These data provided the material for building the city "perception model" from the point of view of its residents and the patterns of the desired settlement.

The research methodology includes the phase of selecting and studying the quantitative parameters characterizing the topology of the plan. To this end, the city plan is represented as a multitude of connections (shortest-distance routes) within the transportation and communication network. Two parameters are used as the values characterizing the topological structure of the plan: the common measure of mutual remoteness of activity centers and the "scale of settlement" (the average of the distances between the places of potential settlement and employment).

The following basic conditions for conducting sociological research are adopted:

1) The working-age population is divided into four social groups by gender and education (secondary and higher). Since the issue in question is choice based on interest, the division into groups defined by the content of labor and business needs proved appropriate;

2) Job vacancies are divided into four quality categories by interest (advancement and promotion opportunities) and remuneration. The nature of work is described through its content and social assessment (salary, education and professional training levels, prestige). Thus, the division of vacancies by interest and remuneration for each social group has two possible evaluations: "interesting and not interesting";

3) The units of observation are homogeneous social groups of working-age population. An individual makes his or her own choice of the "salary and interest" quality according to their capabilities. In addition, the response expresses the desired choice option. This allows identifying the differences between the actual and desired settlement in the context of urban expansion and renovation.

The criterion of time is the most stable factor in behavior and destination choosing. In most of the above-discussed models, a priori hypothesis is that the only objective determining the functioning of the urban system is the minimization of time expenditure. In fact, this parameter can be seen as an "order parameter" that coordinates different interests and objectives. Each destination imposes its special quality upon the objective-minimum time expenditure relation, expressing interest in that particular destination. In this context, time is payment for interest, comparable to other factors.

Uncertainty in the behavior of people when choosing situations and destinations suggests the existence of a second time, an "internal time", which can be regarded as a measure of interest and objectives.

One of the approaches in synergetics is the transformation that provides the transition from "time-reversible description to probable"; its remarkable feature is that it allows the "timing of space," giving it a "temporal dimension," writes I. Prigogine. An important role in this transition is played by the concept of time: "internal time, fundamentally different from astronomical time, although it can also be measured by the clock, but it has a completely 
different meaning, as it arises from random behavior occurring in unstable dynamical systems." By multiple properties, our object—-the city—qualifies as a complex and open (to the flow of people, information, and processes) system capable of development, evolution, and self-organization [14].

Our approach thus implies combining the desired patterns of self-regulation of time expenditure with the purposeful placement of facilities - the centers of gravity. These are also the tasks of forecasting and solving the issues of transportation and all the other major functional subsystems $[15,16]$.

\section{Results}

The results of the sociological survey allowed establishing the trend of settlement on the basis of the effect of the desired choice. The impact of interest significantly modifies the known function of labor gravitation according to the criterion of minimum time expenditure. The closest similarity to it was displayed by the settlement dependency curves of the fourth type of employment for all the social groups and by the graphs of actual settlement in today's city. The study discovered a correlation between the values characterizing the topological structure of the plan: a distinctive "scale of settlement" (average shortest distances between the settlement variant and workplace locations) and the internal heterogeneity of the plan (uneven concentration of facilities and their connections). This allows drafting settlement curves for cities without empirical data.

Introducing the developed model into the preparation of city plans implements design methods taking into account the settlement variants, the intensity of the use of the territory, the preferences of some areas over others, and the solution of transportation problems.

\section{References}

1. D.N. Vlasov, N.V. Danilina, Industrial and Civil Engineering 9, 44-49 (2016)

2. M. Saniroychansyah, Urban Compactness Effects on the Distributions of Healthy Houses in Yogyakarta City (2016)

3. X. Zengqi, J. Siu Lee Lam, A systems framework for the sustainable development of a Port City: A case study of Singapore's policies (Nanyang Technological University, Singapore, 2016)

4. T.Yang, B. Hillier, The Proceedings of 8th International Space Syntax Symposium 8019:1-23, 1-2 (2012)

5. T.A. Vavilova, Bulletin of MGSU, 4 (2009)

6. I.A. Ageev, Bulletin of Tomsk State University, 385 (2014)

7. A.A. Baranov, Academic Bulletin UralNIIproekt RAASN, 3 (2009)

8. C. Ankur, A. Singh, A hybrid multi-criteria decision making method approach for selecting a sustainable location of healthcare waste disposal facility (Indian Institute of Management Rohtak, India, 2016)

9. V. Glazychev, Journal Politia. Analysis. The Chronicle. Forecast 1(64), 147-614 (2012)

10. M.Á. García-Fuentesa, A. Quijanoa, C. de Torrea, R. Garcíaa, P. Compereb, C. Degardb, I. Toméc, European Cities Characterization as Basis towards the Replication of a Smart and Sustainable Urban Regeneration Model (2017).

11. V. Rybchinsky, City designer: Ideas and cities (Strelka Press, Moscow, 2014)

12. M.V. Boykova, I.N. Ilyina, M.G. Salazkin, Forsyth Magazine, 4 (2011) 
13. T.Y. Ovsyannikova, M.N Nikolaenko, Real estate: economics, management 4, 51-56 (2016)

14. B. Hillier, Complexity, Cognition, Urban Planning and Design, 75-92 (2016)

15. D. Mercedes, E.M. Porter, S. Stern, Defining clusters of related industries, Journal of Economic Geography (2015)

16. V.A. Kolyasnikov, Academic Bulletin UralNIIproekt RAASN, 2 (2015) 